\title{
KAJIAN KINERJA KONSULTAN SUPERVISI PROYEK KONSTRUKSI JALAN DI WILAYAH ACEH
}

\author{
Taufik Prawira Hidayah ${ }^{1}$, Anton Soekiman ${ }^{2}$ \\ ${ }^{1)}$ Program Studi Magister Teknik Sipil, Sekolah Pascasarjana Universitas Katholik \\ Parahyangan. Jl. Merdeka No.30 Bandung 40117, \\ email:taufikprawirahidayah@gmail.com \\ ${ }^{2)}$ Fakultas Teknik, Jurusan Teknik Sipil Universitas Katholik Parahyangan \\ J1. Ciumbeleuit No.94 Bandung 40141, email: antonsoekiman@yahoo.com
}

\begin{abstract}
This study was conducted to analyze the factors that most affect the performance and how's performance Supervision Consultant in Aceh region. Respondents in this study amounted to 75 people consisting of supervising consultant residing in Aceh region. Testing the hypothesis in the research done by using path analysis. Descriptive analysis results of this study showing the supervising consultant's performance in Aceh region is good with a mean total of 3.7826, the effect of each variable and a significant variable or the most influence with the performance of a supervision consultant is education variable (X1) with a value of $3 \%$, training variable (X2) with a value of $7.37 \%$, skill variable (X3) with a value of $4.45 \%$, experience variable (X4) with a value of $1.78 \%$, incentive variable (X5) with a value of $0.01 \%$, salary variable (Y1) with a value of $14.9 \%$, motivation variable (Y2) with a value of $0.09 \%$ and a salary variable (Y1) through Training (X2) with value of $11.1 \%$, a salary variable (Y1) through experience (X4) with a value of 6.27\%, motivation variable (Y2) with a value of $0.03 \%$.
\end{abstract}

Keywords: Supervisin consultant, performance, descriptive analysis, path analysis

\begin{abstract}
Abstrak : Penelitian ini dilakukan untuk menganalisa faktor yang paling berpengaruh terhadap kinerja Konsultan Supervisi serta bagaimana kinerja Konsultan Supervisi di wilayah Aceh. Responden dalam penelitian ini berjumlah 75 orang yang terdiri dari konsultan supervisi yang berada di wilayah Aceh. Pengujian hipotesis dalam penelitian dilakukan dengan menggunakan path analysis. Hasil analisis deskriptif dari penelitian ini adalah kinerja konsultan supervisi di wilayah Aceh sudah baik dengan nilai mean total 3,7826, besarnya pengaruh tiap variabel serta variabel yang signifikan atau paling berpengaruh langsung terhadap kinerja seorang konsultan supervisi adalah variabel pendidikan (X1) dengan nilai sebesar 3\%, variabel pelatihan (X2) dengan nilai sebesar 7,37\%, variabel skill (X3) dengan nilai sebesar 4,45\%, variabel pengalaman (X4) dengan nilai sebesar 1,78\%, variabel insentif (X5) dengan nilai sebesar $0,01 \%$, variabel salary (Y1) dengan nilai sebesar $14,9 \%$, variabel motivasi (Y2) dengan nilai sebesar $0,09 \%$ dan variabel salary (Y1) melalui Pelatihan (X2) dengan nilai sebesar $11,1 \%$, variabel salary (Y1) melalui Pengalaman (X4) dengan nilai sebesar 6,27\%, variabel motivasi (Y2) dengan nilai sebesar $0,03 \%$.
\end{abstract}

Kata kunci: konsultan Supervisi, kinerja, analisis deskriptif, path analysis.

Pembangunan jaringan jalan di wilayah

Aceh sangat pesat pasca bencana alam Tsunami yang melanda Aceh pada tahun 2004 yang lalu. Suatu proyek pembangunan jalan dapat dikatakan berhasil jika waktu penyelesaiannya tepat waktu, sesuai dengan anggaran yang dianggarkan serta mutu sesuai dengan spesifikasi. Selain itu faktor lain proyek konstruksi dikatakan memiliki kinerja baik disebabkan oleh adanya pengawasan yang baik Pengawasan merupakan suatu upaya agar kegiatan pekerjaan dilaksanakan 
sesuai dengan yang direncanakan. Proyek yang memiliki kinerja yang baik salah satu sebabnya di akibatkan adanya pengawasan yang baik Supriadi (2004).

Pengawasan proyek (Project

Monitoring) bertujuan untuk :

1. Mengevaluasi dan monitoring realisasi fisik dan financial dan menilai efisiensi dan efektifitasnya secara kuantitatif apakah sesuai dengan rencana kerja.

2. Meneliti dan mengevaluasi kondisi proyek dan memberikan saran-saran atau pengarahan jika terdapat permasalahan yang berdampak pada kemajuan Proyek.

3. Menginformasikan temuan-temuan di lapangan dan memberikan saran-saran konstruktif kepada manajemen

Tujuan penelitian ini mengidentifikasi faktor apakah yang paling mempengaruhi kinerja konsultan supervisi serta seberapa besarnya pengaruh tiap faktor tersebut terhadap kinerja seorang konsultan supervisi khususnya konsultan supervisi yang berada di wilayah Provinsi Aceh. Penelitian ini menggunakan path analysis.

\section{KAJIAN PUSTAKA}

\section{Penelitian yang relevan}

Dalam Michael (2005) dikatakan bahwa faktor-faktor berpengaruh terhadap kinerja diantaranya :
1. Mampu bekerja sesuai dengan spesifikasi dan mengikuti prosedur yang ada

2. Kemampuan berkomunikasi

3. Keahlian interpersonal

4. Mampu bekerja sama dalam tim

5. Inisiatif

6. Memiliki pengetahuan kerja dan sifat profesionalisme

7. Keahlian analitis

8. Produktifitas

9. Memiliki sifat kepemimpinan

10.Berkualitas

Dalam Hasibuan (2005) dikatakan bahwa hal yang berpengaruh terhadap salary/kompensasi yang berpengaruh terhadap kinerja yaitu :

1. Meningkatkan kinerja

2. Ikatan kerjasama

3. Kepuasan kerja

4. Pengadaan efektif

5. Motivasi

6. Stabilitas karyawan

7. Disiplin

Dalam Johnstone et al. (2002) dikatakan kaitan pengalaman terhadap kinerja yaitu:

1. Pengalaman kerja memiliki dasar lebih baik karena pengetahuan yang mereka miliki lebih besar

2. Semakin sering bekerja maka semakin banyak wawasan mengenai pekerjaan yang mereka sering kerjakan

Lubis (2008) mengatakan kaitan motivasi terhadap kinerja yaitu: 
1. Rasa aman dalam bekerja

2. Kebutuhan ekonomis

3. Kepuasan dalam melakukan pekerjaan

4. Rasa ingin tahu akan pekerjaan

5. Menggunakan cara-cara baru

6. Adanya penghargaan pretasi kerja

Adapun faktor yang mempengaruhi kinerja konsultan supervisi menurut Riduwan (2006) adalah :

1. Inisiatif
a. Berfikir positif
b. Kreatifitas

2. Ketepatan waktu
a. Pencapaian
b. prestasi pekerjaan

3. Kualitas pekerjaan

\section{Kepuasan owner}

4. Komunikasi

Menurut Juanim (2004), analisi jalur adalah bagian dari model regresi yang dapat digunakan untuk menganalisi hubungan sebab akibat antar satu variabel dengan variabel lainnya.

\section{Menentukan ukuran sampel}

Teknik pengambilan sampel menggunakan rumus Taro Yamane yang diambil dalam Riduwan (2007) adalah sebagai berikut :

\section{Teknik analisa data}

Analisa data yang dilakukan adalah analisa data kuantitatif. Dalam pembahasan ini hanya dikemukakan jenis skala sikap yang biasa digunakan yaitu skala Likert

$$
\mathrm{n}=\frac{\mathrm{N}}{\mathrm{N} \cdot \mathrm{d}^{2}+1}
$$

\section{Uji normalitas}

Uji normalitas adalah uji yang dilakukan untuk mengecek apakah data penelitian kita berasal dari populasi yang sebarannya normal. Uji ini perlu dilakukan karena semua perhitungan statistik parametric. Uji normalitas bertujuan untuk mengetahui apakah data yang diperoleh dari hasil penelitian berdistribusi normal atau tidak

\section{Uji validitas}

Menurut Sugiyono (2006) Uji validitas adalah suatu langkah pengujian yang dilakukan terhadap isi atau content dari suatu instrumen, dengan tujuan untuk mengukur ketepatan instrumen yang digunakan dalam suatu penelitian. Uji validitas ini bertujuan untuk menguji ketepatan dan kecermatan suatu instrumen pengukuran dalam melakukan fungsi ukurnya, agar data yang diperoleh sesuai dengan tujuan diadakannyapengukuran tersebut

\section{Uji reliabilitas}

Uji reliabilitas adalah proses pengukuran terhadap ketepatan (konsisten) dari suatu instrumen. Pengujian ini dimaksudkan untuk menjamin instrumen yang digunakan merupakan sebuah instrumen yang handal, konsistensi, stabil dan dependibalitas, sehingga bila digunakan 
berkali-kali dapat menghasilkan data yang sama

Konsep dasar analisis jalur (path analysis)

Menurut Juanim (2004), analisis jalur adalah bagian dari model regresi yang dapat digunakan untuk menganalisi hubungan sebab akibat antar satu variabel dengan variabel lainnya. Analisis ini digunakan untuk menguji fit dari matriks korelasi terhadap dua atau lebih model kausal yang sedang dibandingkan dengan peneliti. Beberapa asumsi yang mendasari analisa jalur adalah :

1 Hubungan antar variabel bersifat linear, adaptif dan bersifat normal.

2 Recursivity, hanya sistem aliran kausal ke satu arah artinya tidak ada arah kausalitas yang berbalik.

3 Variabel terikat (endogen) minimal dalam skala ukur interval dan ratio.

4 Menggunakan probability sampling.

5 Observed variables.

6 Model yang dianalisa dianalisis dan diidentifikasi dengan benar berdasarkan teori dan konsep yang relevan.

\section{Uji kecocokan model analisis jalur (path analysis)}

Uji kecocokan model analisis jalur bertujuan untuk menguji kecocokan antara data dengan model yang dibuat. Adapun indikator yang digunakan untuk uji kecocokan model path ini adalah:
1. CMIN/DF (normed Chi Square) Dimana batasan nilai CMIN/DF yang lebih kecil atau sama dengan 2,0 atau $3,0$.

2. GFI (godness of fit index), nilai GFI dikatakan baik adalah $\geq 0,90$

3. AGFI (adjusted GFI), . Tingkat penerimaan yang direkomendasikan adalah bila mempunyai nilai sama atau lebih besar dari 0,9

4. CFI ( comparative fit index), model dikatakan baik apabila memiliki nilai CFI yang mendekati 1 .

5. RMSEA (root mean square error of approximation), dimana batasan Nilai RMSEA lebih kecil atau sama dengan 0,08

6. TLI ( Tuker-Lewis index), dimana Nilai yang direkomendasikan sebagai acuan untuk diterimanya sebuah model adalah lebih besar atau sama dengan 0,9 dan nilai yang mendekati 1

7. NFI ( Normed fit index), suatu model dikatakan fit apabila mempunyai nilai $\mathrm{NFI} \geq 0,9$.

\section{METODOLOGI PENELITIAN}

\section{Faktor yang mempengaruhi kinerja konsultan supervisi}

Faktor dan sub faktor hasil dari studi literatur akan digunakan dalam penelitan ini. Kinerja konsultan supervisi dalam penelitian ini dipengaruhi oleh 7 faktor utama yaitu:

1. Pendidikan (Tabitha et al., 2013)

2. Pelatihan (Tabitha et al., 2013) 
3. Skill (Hoai et al., 2008)

4. Pengalaman (Johnstone et al., 2002)

5. Insentif (Mangkupawira, 2002)

6. Salary (Hasibuan, 2005)

7. Motivasi (Lubis, 2008)

Selanjutnya dari ke-tujuh faktor inilah nantinya akan dikaji seberapa besar faktor ini berpengaruh terhadap kinerja konsultan supervisi dan faktor manakah yang paling berpengaruh terhadap kinerja konsultan supervisi pada pelaksanaan proyek konstruksi jalan di Provinsi Aceh

Pengolahan data yang dilakukan pada penelitian ini adalah sebagai berikut:

1. Analisis deskriptif

2. Uji normalitas

3. Uji validitas

4. Uji reliabilitas

5. Analisis jalur (path analysis)

\section{HASIL DAN PEMBAHASAN}

Data dalam penelitian yang diperoleh dari kuesioner berasal dari pihak Konsultan supervisi yang berada di wilayah Provinsi Aceh, penyebaran kuesioner dilakukan dalam kurun waktu Februari 2015 sampai dengan Maret 2015 yang dilakukan dengan cara penyampaian langsung kepada pihak Konsultan Supervisi. Kuesioner yang disebarkan ada sebanyak 75 set dimana kuesioner yang dikembalikan sebanyak 69 set dengan respon rate pengisian kuesioner sebesar $92 \%$.

\section{Deskripsi Pengalaman Kerja Responden}

Dari hasil data yang diperoleh dari penyebaran kuesioner diperoleh data pengalaman kerja responden sebagai berikut:

Tabel 1 . Pengalaman Kerja Responden

\begin{tabular}{|c|c|}
\hline $\begin{array}{c}\text { LAMA BEKERJA } \\
\text { (TAHUN) }\end{array}$ & ORANG RESPONDEN \\
\hline 1-5 Tahun & 4 \\
\hline 6-10 Tahun & 40 \\
\hline $11-15$ Tahun & 12 \\
\hline 16-20 Tahun & 13 \\
\hline
\end{tabular}

\section{Deskripsi Pendidikan Kerja Responden}

Dari hasil data yang diperoleh dari penyebaran kuesioner diperoleh data tingkat pendidikan responden sebagai berikut:

Tabel 2 . Tingkat Pendidikan Responden

\begin{tabular}{|c|c|}
\hline $\begin{array}{c}\text { PENDIDIKAN } \\
\text { TERAKHIR }\end{array}$ & ORANG RESPONDEN \\
\hline D3 & 0 \\
\hline S1 & 64 \\
\hline S2 & 5 \\
\hline S3 & 0 \\
\hline
\end{tabular}

\section{Deskripsi Jabatan Responden}

Dari hasil data yang diperoleh dari penyebaran kuesioner diperoleh data jabatan responden sebagai berikut:

Tabel 3 . Jabatan Responden

\begin{tabular}{|c|c|}
\hline JABATAN & $\begin{array}{c}\text { ORANG } \\
\text { RESPONDEN }\end{array}$ \\
\hline SE & 19 \\
\hline CI & 25 \\
\hline QE & 18 \\
\hline INSPECTOR & 3 \\
\hline SURVEYOR & 0 \\
\hline LAB TECHNICIAN & 4 \\
\hline
\end{tabular}




\section{Deskripsi Jenis Pekerjaan Yang Pernah}

\section{Diawasi Responden}

Dari hasil data yang diperoleh dari penyebaran kuesioner diperoleh data jenis pekerjaan jalan yang pernah diawasi oleh responden sebagai berikut:

Tabel 4 . Jenis Pekerjaan Yang Pernah Diawasi

\begin{tabular}{|c|c|}
\hline JENIS PEKERJAAN & ORANG RESPONDEN \\
\hline $\begin{array}{c}\text { Pembangunan jalan } \\
\text { baru }\end{array}$ & 18 \\
\hline Peningkatan jalan baru & 33 \\
\hline $\begin{array}{c}\text { Rehabilitasi dan } \\
\text { rekonstruksi }\end{array}$ & 18 \\
\hline lainnya & 0 \\
\hline
\end{tabular}

\section{Deskripsi Jenis Kompleksitas Pekerjaan}

\section{Yang Pernah Diawasi Responden}

Dari hasil data yang diperoleh dari penyebaran kuesioner diperoleh data kompleksitas jenis pekerjaan jalan yang pernah diawasi oleh responden sebagai berikut:

Tabel 5 . Kompleksitas Jenis Pekerjaan Yang Pernah Diawasi

\begin{tabular}{|c|c|}
\hline $\begin{array}{c}\text { KOMPLEKSITAS } \\
\text { PEKERJAAN }\end{array}$ & $\begin{array}{c}\text { ORANG } \\
\text { RESPONDEN }\end{array}$ \\
\hline Jalan provinsi & 27 \\
\hline Jalan kabupaten & 27 \\
\hline Jalan perkotaan & 15 \\
\hline Jalan tol & 0 \\
\hline
\end{tabular}

\section{Hasil Analisis Deskirptif}

Penilaian analisa deskriptif dilakukan dengan melihat rata-rata (means) yang diperoleh untuk menarik kesimpulan.

Berikut kriteria penilaian yang dilakukan:
Rata-rata $=$

Total skor jawaban responden per indikator Banyaknya jumlah responden

Hasil dari nilai rata-rata dipetakan ke rentang skala yang mempertimbangkan informasi interval berikut ini Interval $=$

Nilai tertinggi - Nilai terendah Banyaknya Kelas

Adapun rentang skala penilaiannya adalah sebagai berikut:

\begin{tabular}{|c|c|c|c|c|}
\hline $\begin{array}{c}\text { Tidak baik } \\
\text { (Sangat } \\
\text { rendah) }\end{array}$ & $\begin{array}{l}\begin{array}{c}\text { Kurang } \\
\text { baik }\end{array} \\
\text { (Rendah) }\end{array}$ & $\begin{array}{c}\begin{array}{c}\text { Cukup } \\
\text { baik }\end{array} \\
\text { Sedang }\end{array}$ & $\begin{array}{l}\text { Baik } \\
\text { (Ting } \\
\text { gi) }\end{array}$ & $\begin{array}{l}\text { Sangat bail } \\
\text { (Sangat } \\
\text { tinggi) }\end{array}$ \\
\hline 1 & & & & \\
\hline
\end{tabular}

Gambar 1 . Rentang penilaian

Adapun hasil penilaian analisis deskriptif yaitu:

Tabel 6 . Hasil Penilaian Uji Deskriptif

\begin{tabular}{|c|c|c|}
\hline FAKTOR & $\begin{array}{c}\text { NILAI } \\
\text { MEAN } \\
\text { TOTAL }\end{array}$ & KETERANGAN \\
\hline $\begin{array}{c}\text { Pendidikan } \\
(\mathrm{X} 1)\end{array}$ & 3,8290 & Tinggi \\
\hline $\begin{array}{c}\text { Pelatihan } \\
(\mathrm{X} 2)\end{array}$ & 3,1691 & Cukup baik \\
\hline $\begin{array}{c}\text { Skill (X3) } \\
\text { (X4) }\end{array}$ & 4,1350 & Sangat tinggi \\
\hline $\begin{array}{c}\text { Pengalaman } \\
\text { Tinggi }\end{array}$ \\
\hline $\begin{array}{c}\text { Insentif (X5) } \\
\text { Salary (Y1) }\end{array}$ & 3,2493 & Cukup baik \\
\hline Motivasi (Y2) & 2,7702 & Sangat baik \\
\hline Kinerja (Y3) & 3,7826 & Tinggi \\
\hline
\end{tabular}

\section{Analisis jalur (path analysis)}

pengujian path dilakukan dengan menggunakan perangkat lunak (software) 
AMOS, diagram jalur dapat dilihat pada gambar 2. Berikut adalah hasil pengujian kecocokan model analisis jalur:

Tabel 7. Hasil Uji Kecocokan Model Path

\begin{tabular}{|c|c|c|c|}
\hline Model & $\begin{array}{c}\text { Kriteria } \\
\text { Nilai }\end{array}$ & $\begin{array}{c}\text { Ha } \\
\text { sil }\end{array}$ & Kesimpulan \\
\hline $\begin{array}{c}\text { CMIN } \\
\text { /DF }\end{array}$ & $\leq 3,00$ & $\begin{array}{c}1.0 \\
04\end{array}$ & $\begin{array}{l}\text { Memenuhi syarat } \\
\text { secara Signifikan }\end{array}$ \\
\hline GFI & $\geq 0,90$ & 983 & $\begin{array}{c}\text { Memenuhi syarat } \\
\text { secara Signifikan }\end{array}$ \\
\hline AGFI & $\geq 0,90$ & $\begin{array}{c}.87 \\
4\end{array}$ & $\begin{array}{c}\text { Hampir memenuhi } \\
\text { syarat }\end{array}$ \\
\hline CFI & $\geq 0,90$. & $\begin{array}{c}1.0 \\
00\end{array}$ & $\begin{array}{c}\text { Memenuhi syarat } \\
\text { secara Signifikan }\end{array}$ \\
\hline RMSE & $\leq 0,08$. & $\begin{array}{c}.00 \\
\text { A }\end{array}$ & $\begin{array}{l}\text { Memenuhi syarat } \\
\text { secara Signifikan }\end{array}$ \\
\hline TLI & $\geq 0,90$. & $\begin{array}{c}.99 \\
9\end{array}$ & $\begin{array}{l}\text { Memenuhi syarat } \\
\text { secara Signifikan }\end{array}$ \\
\hline NFI & $\geq 0,90$. & $\begin{array}{c}.97 \\
0\end{array}$ & $\begin{array}{l}\text { Memenuhi syarat } \\
\text { secara Signifikan }\end{array}$ \\
\hline
\end{tabular}

Uji signifikansi secara individual analisis jalur dicari dengan membandingkan antara nilai probabilitas 0,05 dengan nilai probabilitas sig.

Dasar pengambilan keputusan sebagai berikut:

Jika nilai probabilitas sig 0,05 lebih kecil atau sama dengan nilai probabilitas atau $(\mathrm{SIG} \leq 0,05)$,

1. maka Ha diterima dan Ho ditolak artinya signifikan

2. Jika nilai probabilitas sig 0,05 lebih kecil atau sama dengan nilai probabilitas atau $(\mathrm{SIG} \geq 0,05)$, maka Ha ditolak dan Ho diterima artinya tidak signifikan

Dengan mengunakan perangkat lunak AMOS v22 diperoleh hasil :

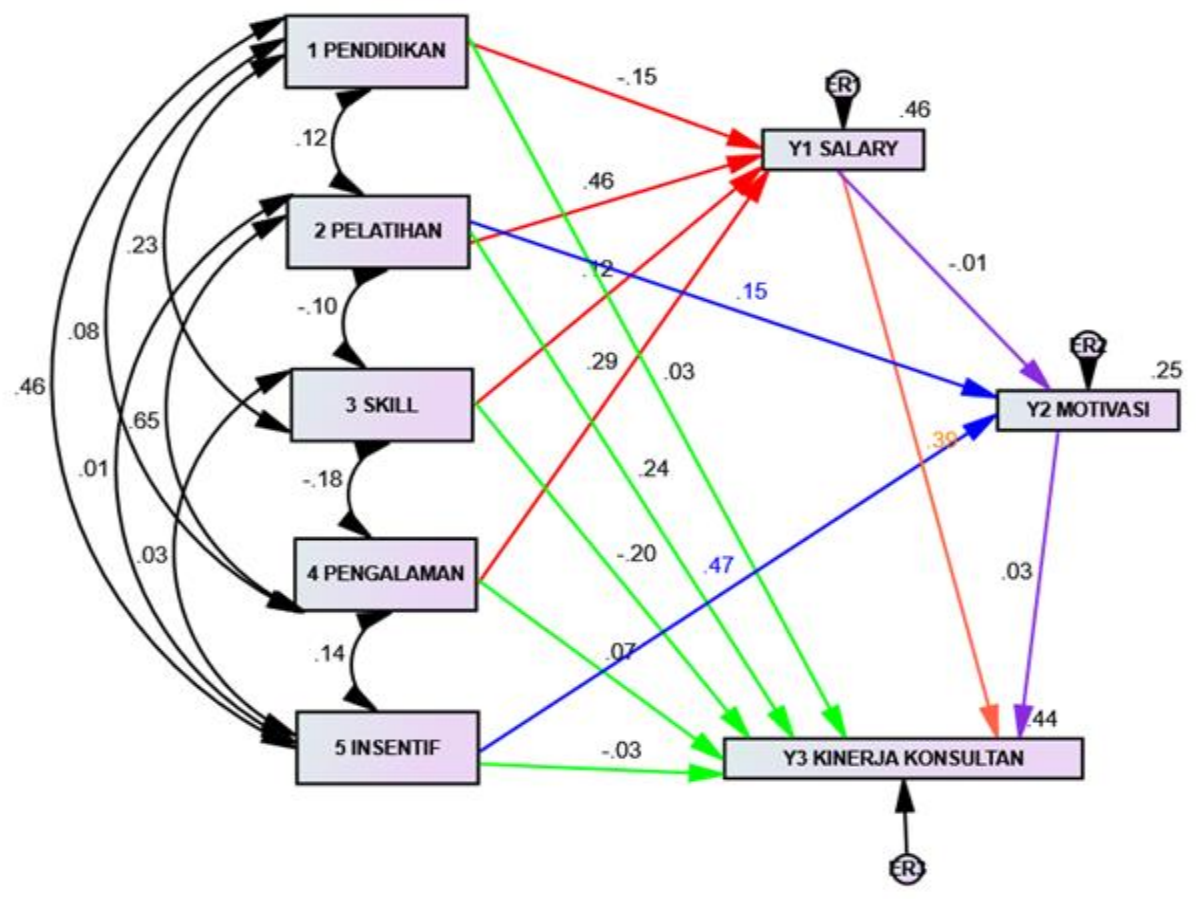

Gambar 2. Model Estimasi Parameter Kinerja Konsultan Supervisi 
Tabel 8. Hasil Pengujian Hipotesis Secara Individual Model Path

\begin{tabular}{|l|c|c|c|c|c|c|c|c|}
\hline \multicolumn{2}{|c|}{ Variable to } & Estimate & S.E. & C.R. & P & Label & alpha 5\% \\
\hline Mean_y1 & $<---~$ & Mean_X1 & $-0,136$ & 0,084 & $-1,626$ & 0,104 & par_1 & Tidak Signifikan \\
\hline Mean_y1 & $<---$ & Mean_X2 & 0,424 & 0,108 & 3,933 & $* * *$ & par_2 & Signifikan \\
\hline Mean_y1 & $<---$ & Mean_X3 & 0,195 & 0,151 & 1,29 & 0,197 & par_3 & Tidak Signifikan \\
\hline Mean_y1 & $<---$ & Mean_X4 & 0,31 & 0,127 & 2,448 & 0,014 & par_4 & Signifikan \\
\hline Mean_y2 & $<---$ & Mean_y1 & $-0,008$ & 0,169 & $-0,045$ & 0,964 & par_12 & Tidak Signifikan \\
\hline Mean_y2 & $<---$ & Mean_X5 & 0,555 & 0,123 & 4,498 & $* * *$ & par_10 & Signifikan \\
\hline Mean_y2 & $<---$ & Mean_X2 & 0,175 & 0,155 & 1,129 & 0,259 & par_24 & Tidak Signifikan \\
\hline Mean_y3 & $<---$ & Mean_X1 & 0,04 & 0,137 & 0,29 & 0,772 & par_6 & Tidak Signifikan \\
\hline Mean_y3 & $<---~$ & Mean_X2 & 0,309 & 0,174 & 1,779 & 0,075 & par_7 & Tidak Signifikan \\
\hline Mean_y3 & $<---$ & Mean_y2 & 0,033 & 0,117 & 0,285 & 0,776 & par_13 & Tidak Signifikan \\
\hline Mean_y3 & $<---$ & Mean_y1 & 0,543 & 0,173 & 3,141 & 0,002 & par_11 & Signifikan \\
\hline Mean_y3 & $<---$ & Mean_X3 & $-0,444$ & 0,219 & $-2,03$ & 0,042 & par_8 & Signifikan \\
\hline Mean_y3 & $<---$ & Mean_X4 & 0,103 & 0,191 & 0,54 & 0,589 & par_5 & Tidak Signifikan \\
\hline
\end{tabular}

Tabel 8 merupakan nilai variabel yang signifikan, dengan melihat nilai $\mathrm{P}$ dimana jika nilai $\mathrm{P}$ atau $\mathrm{SIG}($ signifikansi) $<0,05$ maka hipotesis diterima dapat diambil kesimpulan terhadap hipotesis yaitu:

H1: PENDIDIKAN tidak berkontribusi secara signifikan terhadap SALARY.

H2: PELATIHAN berkontribusi secara signifikan terhadap SALARY.

H3: SKILL tidak berkontribusi secara signifikan terhadap SALARY.

H4: PENGALAMAN berkontribusi secara signifikan terhadap SALARY.

H5: SALARY tidak berkontribusi secara signifikan terhadap MOTIVASI

H6: INSENTIF berkontribusi secara signifikan terhadap MOTIVASI

H7: PELATIHAN tidak berkontribusi secara signifikan terhadap MOTIVASI

H8: PENDIDIKAN tidak berkontribusi secara signifikan terhadap KINERJA
H9: PELATIHAN berkontribusi secara signifikan terhadap KINERJA

H10: MOTIVASI tidak berkontribusi secara signifikan terhadap KINERJA

H11: SALARY berkontribusi secara signifikan terhadap KINERJA

H12: SKILL berkontribusi secara signifikan terhadap KINERJA

H13: PENGALAMAN tidak berkontribusi secara signifikan terhadap KINERJA

H14: INSENTIF tidak berkontribusi secara signifikan terhadap KINERJA

Hasil perhitungan dapat dilihat pada tabel dibawah. 
Tabel 9 Nilai Total Pengaruh Y1 Analysis)

\begin{tabular}{|l|c|}
\hline \multicolumn{1}{|c|}{ Pengaruh (Y1) } & Nilai \\
\hline langsung X1-->Y1 & 0,022801 \\
\hline tdk lgsg X1-X2-->Y1 & $-0,00811$ \\
\hline tdk lgsg X1-X3-->Y1 & $-0,00422$ \\
\hline tdk lgsg X1-X4-->Y1 & $-0,00373$ \\
\hline Total X1-->Y1 & 0,006736 \\
\hline langsung X2-->Y1 & 0,214369 \\
\hline tdk lgsg X2-X1-->Y1 & $-0,00811$ \\
\hline tdk lgsg X2-X3-->Y1 & $-0,00543$ \\
\hline tdk lgsg X2-X4-->Y1 & 0,087172 \\
\hline Total X2 -->Y1 & 0,287997 \\
\hline langsung X3-->Y1 & 0,014641 \\
\hline tdk lgsg X3-X1-->Y1 & $-0,00422$ \\
\hline tdk lgsg X3-X2-->Y1 & $-0,00543$ \\
\hline tdk lgsg X3-X4-->Y1 & $-0,0062$ \\
\hline Total X3-->Y1 & $-0,00121$ \\
\hline langsung X4-->Y1 & 0,084681 \\
\hline tdk lgsg X4-X1-->Y1 & $-0,00373$ \\
\hline tdk lgsg X4-X2-->Y1 & 0,087172 \\
\hline tdk lgsg X4-X3-->Y1 & $-0,0062$ \\
\hline Total X4-->Y1 & 0,161921 \\
\hline $\begin{array}{l}\text { Total pengaruh simultan- } \\
\text {->Y1 }\end{array}$ & 0,455443 \\
\hline
\end{tabular}

Tabel 10 Nilai Total Pengaruh Y2 (Path Analysis)

\begin{tabular}{|l|c|}
\hline \multicolumn{1}{|c|}{ Pengaruh (Y2) } & Nilai \\
\hline langsung X2--> Y2 & 0,023104 \\
\hline tdk 1sgs X2-X5--> Y2 & 0,000719 \\
\hline Total X2--> Y2 & 0,023823 \\
\hline langsung X5--> Y2 & 0,223729 \\
\hline tdk lsgs X5-X2--> Y2 & 0,000719 \\
\hline Total X5--> Y2 & 0,224448 \\
\hline langsung Y1--> Y2 & 0,0001 \\
\hline $\begin{array}{l}\text { Total pengaruh } \\
\text { Simultan --> Y2 }\end{array}$ & 0,248371 \\
\hline
\end{tabular}

Tabel 11 Nilai Total Pengaruh Y3 (Path Analysis)

\begin{tabular}{|c|c|}
\hline Pengaruh (Y3) & Nilai \\
\hline Langsung Y1-->Y3 & 0,149769 \\
\hline Langsung Y2-->Y3 & 0,0009 \\
\hline Langsung X1--> Y3 & 0,001024 \\
\hline Langsung X2-->Y3 & 0,0576 \\
\hline Langsung X3--> Y3 & 0,038809 \\
\hline Langsung X4--> Y3 & 0,004761 \\
\hline Langsung X5-->Y3 & 0,000676 \\
\hline Total pengaruh langsung & 0,254 \\
\hline Tidak Langsung X1-Y1--> Y3 & 0,002607 \\
\hline Tidak Langsung X2-Y1--> Y3 & 0,111455 \\
\hline Tidak Langsung X3-Y1-->Y3 & $-0,00047$ \\
\hline Tidak Langsung X4-Y1--> Y3 & 0,062663 \\
\hline Tidak Langsung Y1-Y2-->Y3 & 0,000003 \\
\hline Tidak Langsung X2-Y2-->Y3 & 0,000715 \\
\hline Tidak Langsung X5-Y2-->Y3 & 0,006733 \\
\hline $\begin{array}{l}\text { Total pengaruh Tidak } \\
\text { langsung }\end{array}$ & 0,183707 \\
\hline $\begin{array}{l}\text { Total pengaruh } \\
\text { simultan -->Y3 }\end{array}$ & 0,437707 \\
\hline
\end{tabular}

Tabel 12 Nilai Pengaruh Terhadap Kinerja (Y3)

\begin{tabular}{|l|c|r|}
\hline \multicolumn{1}{|c|}{ Pengaruh } & Pada & \multicolumn{1}{c|}{ Nilai } \\
\hline langsung x1 & $\mathrm{y} 3$ & 0,0010 \\
\hline Tidak langsung x1-x2 & $\mathrm{y} 3$ & 0,0009 \\
\hline Tidak langsung x1-x3 & $\mathrm{y} 3$ & $-0,0015$ \\
\hline Tidak langsung x1-x4 & $\mathrm{y} 3$ & 0,0002 \\
\hline Tidak langsung x1-x5 & $\mathrm{y} 3$ & $-0,0004$ \\
\hline Total x1 & & 0,0003 \\
\hline langsung x2 & $\mathrm{y} 3$ & 0,0576 \\
\hline Tidak langsung x2-x1 & $\mathrm{y} 3$ & 0,0009 \\
\hline Tidak langsung x2-x3 & $\mathrm{y} 3$ & 0,0046 \\
\hline Tidak langsung x2-x4 & $\mathrm{y} 3$ & 0,0107 \\
\hline Tidak langsung x2-x5 & $\mathrm{y} 3$ & $-0,0001$ \\
\hline Total x2 & & 0,0737 \\
\hline langsung x3 & $\mathrm{y} 3$ & 0,0388 \\
\hline Tidak langsung x3-x1 & $\mathrm{y} 3$ & $-0,0015$ \\
\hline Tidak langsung x3-x2 & $\mathrm{y} 3$ & 0,0046 \\
\hline Tidak langsung x3-x4 & $\mathrm{y} 3$ & 0,0024 \\
\hline Tidak langsung x3-x5 & $\mathrm{y} 3$ & 0,0001 \\
\hline
\end{tabular}




\begin{tabular}{|l|c|c|l|c|r|}
\hline \multicolumn{1}{|c|}{ Pengaruh } & Pada & Nilai & \multicolumn{1}{c|}{ Pengaruh } & Pada & \multicolumn{1}{c|}{ Nilai } \\
\hline Total x3 & & 0,0445 & langsung $\mathrm{x} 5$ & $\mathrm{y} 3$ & 0,0007 \\
\hline langsung $\mathrm{x} 4$ & $\mathrm{y} 3$ & 0,0048 & Tidak langsung $\mathrm{x} 5-\mathrm{x} 1$ & $\mathrm{y} 3$ & $-0,0004$ \\
\hline Tidak langsung $\mathrm{x} 4-\mathrm{x} 1$ & $\mathrm{y} 3$ & 0,0002 & Tidak langsung $\mathrm{x} 5-\mathrm{x} 2$ & $\mathrm{y} 3$ & $-0,0001$ \\
\hline Tidak langsung $\mathrm{x} 4-\mathrm{x} 2$ & $\mathrm{y} 3$ & 0,0107 & Tidak langsung $\mathrm{x} 5-\mathrm{x} 3$ & $\mathrm{y} 3$ & 0,0001 \\
\hline Tidak langsung $\mathrm{x} 4-\mathrm{x} 3$ & $\mathrm{y} 3$ & 0,0024 & Tidak langsung $\mathrm{x} 5-\mathrm{x} 4$ & $\mathrm{y} 3$ & $-0,0003$ \\
\hline Tidak langsung $\mathrm{x} 4-\mathrm{x} 5$ & $\mathrm{y} 3$ & $-0,0003$ & Total $\mathrm{x} 5$ & & 0,0001 \\
\hline Total $\mathrm{x} 4$ & & 0,0178 & Total Simultan & & 0,1364 \\
\hline
\end{tabular}

Tabel 13. Ringkasan Hasil Estimasi

\begin{tabular}{|c|c|c|c|c|c|c|c|}
\hline \multirow{2}{*}{$\begin{array}{c}\text { Variabel } \\
\text { Model Salary } \\
\end{array}$} & \multirow[t]{2}{*}{ Pengaruh Langsung } & \multicolumn{4}{|c|}{$\begin{array}{c}\text { Pengaruh Tidak Langsung } \\
\text { (melalui) }\end{array}$} & \multirow[t]{2}{*}{\begin{tabular}{|c|} 
Errorvariance \\
$\varepsilon$
\end{tabular}} & \multirow[t]{2}{*}{ RSquared } \\
\hline & & $\mathrm{X} 1$ & $\mathrm{X} 2$ & $\mathrm{X} 3$ & $\mathrm{X} 4$ & & \\
\hline Pendidikan(X1) -> Salary (Y1) & 0,0228 & - & $-0,0081099$ & $-0,0042206$ & $-0,003735$ & \multirow{4}{*}{0,73} & \multirow{4}{*}{0,46} \\
\hline Pelatihan (X2) -> Salary (Y1) & 0,2144 & $-0,0081099$ & \begin{tabular}{|c|}
- \\
\end{tabular} & \begin{tabular}{|l|}
$-0,0054342$ \\
\end{tabular} & 0,087172 & & \\
\hline Skill (X3) -> Salary (Y1) & 0,0146 & $-0,0042206$ & $-0,0054342$ & - & $-0,006197$ & & \\
\hline Pengalaman (X4) -> Salary (Y1) & 0,0847 & $-0,003735$ & 0,0871723 & $-0,0061971$ & - & & \\
\hline Model Motivasi & & $\mathrm{X} 2$ & $\mathrm{X5}$ & & & & \\
\hline Pelatihan(X2) -> Motivasi (Y2) & 0,023104 & - & 0,000719 & & & \multirow{3}{*}{0,87} & \multirow{3}{*}{0,25} \\
\hline Insentif(X5) -> Motivasi (Y2) & 0,223729 & 0,000719 & - & & & & \\
\hline Salary (Y1) -> Motivasi (Y2) & 0,0001 & - & - & & & & \\
\hline Model Kinerja & & Y1 & $\mathrm{Y2}$ & & & & \\
\hline Pendidikan(X1) -> Kinerja (Y3) & 0,001024 & 0,0026066 & - & & & \multirow{7}{*}{0,75} & \multirow{7}{*}{0,44} \\
\hline Pelatihan (X2) -> Kinerja (Y3) & 0,0576 & 0,1114549 & 0,0007147 & & & & \\
\hline Skill $(\mathrm{X} 3)$-> Kinerja $(\mathrm{Y} 3)$ & 0,038809 & $-0,0004686$ & \begin{tabular}{|l|}
- \\
\end{tabular} & & & & \\
\hline Pengalaman (X4) -> Kinerja (Y3) & 0,004761 & 0,0626635 & - & & & & \\
\hline Insentif $(\mathrm{X} 5)$-> Kinerja (Y3) & 0,000676 & - & 0,0067334 & & & & \\
\hline Salary (Y1) -> Kinerja (Y3) & 0,149769 & 0,000003 & - & & & & \\
\hline Motivasi (Y2) -> Kinerja (Y3) & 0,0009 & - & - & & & & \\
\hline
\end{tabular}

Dari tabel 8 dan tabel 13 Hipotesis berkontribusi secara signifikan yaitu :

1. Secara individual Pelatihan (X2) memberikan pengaruh secara langsung sebesar 21,4\% terhadap salary (Y1).

2. Secara individual Pengalaman (X4) memberikan pengaruh secara langsung sebesar 8,47\% terhadap salary (Y1).

3. Secara individual insentif (X5) memberikan pengaruh secara langsung sebesar 22,3\% terhadap motivasi (Y2).
4. Secara individual salary memberikan pengaruh secara langsung sebesar 14,9\% terhadap kinerja (Y3).

5. Secara individual Skill memberikan pengaruh secara langsung sebesar 3,88\% terhadap kinerja (Y3).

\section{KESIMPULAN DAN SARAN}

Dari hasil pengolahan data dan analisis yang telah dilakukan diperoleh kesimpulan: 


\section{Kesimpulan}

A. Kinerja konsultan supervisi jalan di wilayah Provinsi Aceh sudah baik hal ini dapat dilihat dari nilai mean total yaitu sebesar 3,7826

B. Terdapat 7 faktor yang dianggap berpengaruh terhadap kinerja konsultan supervisi di wilayah Aceh dengan masing-masing besar kontribusi pengaruhnya terhadap kinerja yaitu:

1. Pendidikan (X1) sebesar : sebesar 3\%

2. Pelatihan (X2) sebesar : $7,37 \%$

3. Skill (X3) sebesar : $4,45 \%$

4. Pengalaman (X4) sebesar : $1,78 \%$

5. Insentif (X5) sebesar : 0,01\%

6. Salary (Y1) sebesar : 14,9\%

7. Motivasi (Y2) sebesar : 0,09\%

Dari hasil diatas pengaruh terbesar langsung yang mempengaruhi kinerja konsultan supervisi di wilayah Aceh adalah salary selain itu juga selain pengaruh langsung salary dipengaruhi oeh faktor-faktor lainnya yang cukup berpengaruh yaitu faktor pelatihan dan pengalaman, dari hal ini dapat diambil upaya agar dapat meningkatkan kinerja konsultan supervisi di wilayah Aceh agar diberikan pelatihan dari pihak-pihak terkait dengan jumlah dan jangka waktu pelatihan yang diatur sedemikian rupa sesuai dengan kebutuhan di proyek, hal ini guna meningkatkan kinerja seorang konsultan supervisi serta tidak luput Volume 1, No. 2, Juli 2015 pengalaman bekerja seorang konsultan supervisi harus diperhatikan dimana pengalaman dijadikan syarat tenaga ahli dalam proses tender, jika faktor salary, pelatihan dan pengalaman diperhatikan oleh pihak pengguna jasa maupun penyedia jasa hal ini akan berdampak pada kinerja seorang konsultan supervisi.

\section{Saran}

1. Untuk penelitian selanjutnya coba diterapkan pada daerah yang lain,dikarenakan faktor yang mempengaruhi kinerja konsultan supervisi ditiap daerah kemungkinan berbeda.

2. Dicoba dianalisis dengan menggunakan faktor-faktor yang lain.

3. Dicoba dianalisis dengan menggunakan metoda yang lain.

\section{DAFTAR PUSTAKA}

Amstrong , Michael, 2005, Manajemen Sumber Daya Manusia, PT.Elexmedia Komputindo.2 Jakarta.

Hasibuan, Melayu.S.P, 2005, Manajemen Sumber Daya Manusia, Edisi Revisi.Jakarta; PT.Bumi Aksara.

Hoai,L.L., Lee.Y.D., and Lee, J.Y, 2008, Delay and Cost Overruns In Vietnam Large Construction Project: A Comparison With Other Selected Country, KSCE Journal Of Civil Engineering, 12 (6),367-377.November Johnston, M. W., Parrasuraman,A.,Futrell,C. $\quad$ M., \& 
Black, W.C, 2002, A longitudinal assessment of the impact of selected organizational influences on salespeople's organizational commitment during early employment, Journal of Marketing science, 27:333344

Juanim, 2004, Analisis jalur dalam riset pemasaran-teknik pengolahan data SPSS dan Lisrel, Bandung: Penerbit Fakultas Ekonomi UNPAS.

Lubis, Khairul Akhir, 2008, Pengaruh Pelatihan dan Motivasi Kerja Terhadap Kinerja Karyawan PT.Perkebunan Nusantara IV (PERSERO) MEDAN, Tesis, Program Pasca Sarjana Universitas Sumatera Utara, Medan.

Riduwan, 2006, Kontribusi Kompetensi Profesional dan Motivasi Kerja Terhadap Kinerja Dosen, Tesis program pasacasarjana UPI.Tesis tidak diterbitkan.
Supriyadi, Iwan, 2004, Peran Konsultan

Pemgawas Terhadap Peningkatan Kinerja Proyek Pembangunan PLTA di Indonesia (Studi Kasus Proyek PLTA di Lingkungan Nippon Koei Co.Ltd), Tesis Program Pasca Sarjana Teknik UI.Depok. hal.8.

Sugiyono, 2006, Statistika Untuk Penelitian, Cetakan Ketujuh, Bandung: CV. Alfabeta.

Tabitha Insani Maranatha Simbolon, 2013, Faktor-Faktor Yang Mempengaruhi Kinerja Pemeriksa Pajak di KPP Pratam Denpasar Timur dan Badung Selatan, Jurnal akuntansi Universitas Udayana.Bali. 